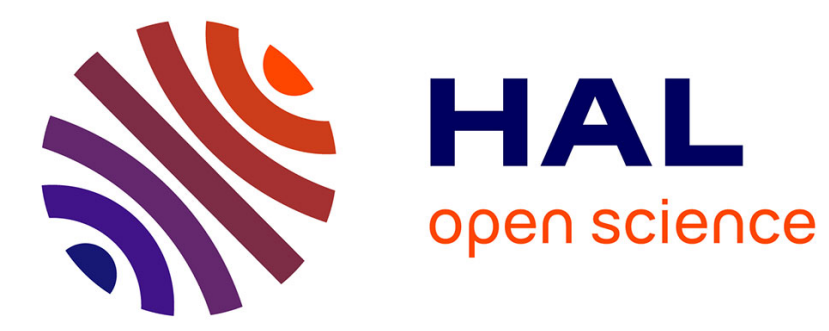

\title{
Plant Symbionts Are Engineers of the Plant-Associated Microbiome
}

Stéphane Uroz, Pierre-Emmanuel Courty, P. Oger

\section{To cite this version:}

Stéphane Uroz, Pierre-Emmanuel Courty, P. Oger. Plant Symbionts Are Engineers of the Plant-Associated Microbiome. Trends in Plant Science, 2019, 24 (10), pp.905-916. 10.1016/j.tplants.2019.06.008 . hal-02334474

\section{HAL Id: hal-02334474 \\ https://hal.science/hal-02334474}

Submitted on 4 Nov 2020

HAL is a multi-disciplinary open access archive for the deposit and dissemination of scientific research documents, whether they are published or not. The documents may come from teaching and research institutions in France or abroad, or from public or private research centers.
L'archive ouverte pluridisciplinaire HAL, est destinée au dépôt et à la diffusion de documents scientifiques de niveau recherche, publiés ou non, émanant des établissements d'enseignement et de recherche français ou étrangers, des laboratoires publics ou privés. 
1 Plant symbionts are engineers of the plant-associated microbiome

2

3 Uroz, S. ${ }^{1,2,3^{*}}$, Courty, P. E. ${ }^{4}$, Oger, P. $^{5}$

4

5

6

71 INRA, UMR1136, «Interactions Arbres-Microorganismes», F-54280 Champenoux, France

82 Université de Lorraine, UMR1136, «Interactions Arbres-Microorganismes», F-54500 Vandoeuvre-lès-Nancy,

9 France

103 INRA, UR1138, «Biogéochimie des écosystèmes forestiers», F-54280 Champenoux, France

114 Agroécologie, AgroSup Dijon, CNRS, Univ. Bourgogne, INRA, Univ. Bourgogne Franche-Comté, F-21000

12 Dijon, France

135 Université Lyon, INSA de Lyon, CNRS UMR 5240, Villeurbanne, France

14

15

16

17

18

19 * Corresponding author: Mailing address:

20 INRA-Université de Lorraine, Interactions Arbres Micro-organismes, UMR 1136, 54280 Champenoux, France.

21 Phone: +33 (0)3 833940 81, Fax: +33 (0)3 833940 69. E-mail: stephane.uroz@inra.fr 


\section{Abstract:}

3 Throughout their life plants interact with environmental microorganisms. The realization that these interactions

4 determine plant development, nutrition and fitness in a dynamic and stressing environment is the basis for the

5 holobiont concept, in which plants and plant-associated microbes are not considered as independent entities, but

6 as a whole evolutionary unit. The main question remaining open concerns the dynamic of this holobiont and

7 whether it is modeled by microbial members of this holobiont or solely by the plant. Interpreting our current

8 knowledge of plant-microbe interaction, and especially the plant endosphere, we can show that the establishment

9 of symbiosis directly and indirectly conditions the plant-associated microbiome, e.g. that microbes within the

10 holobiont shape the structure and composition of the phytomicrobiome, and thus shape the structure of the

11 holobiont. We propose to define the impact of the symbiont on the plant microbiome as the symbiosis cascade

12 effect', in which symbionts and their plant host jointly shape the plant microbiome.

13

14 Key words: symbiosis, endosphere, mutualistic, parasitic, plant, microbiome, phytomicrobiome, interaction,

15 ecological engineer, cascade effect, phytobiome 
Microorganisms play a crucial role in environmental geochemical cycles and in plant nutrition and

3 development. Some microorganisms have evolved the ability to establish symbiotic interactions with their host,

4 be they mutualistic (positive impact), commensalistic (no visible impact), or parasitic (negative impact). Many of

5 these microorganisms are recruited from the plant environment, while others are vertically transferred such as

6 the endophytes contained into the seeds. Symbioses play a key role in plant life, potentially affecting even plant

7 speciation [1,2]. Most of these symbiotic interactions have been considered only from a single angle, such as the

8 symbiont, the plant host, or the interaction between both. Rarely have we considered how the establishment of

9 the symbiont and response of the plant influence the recruitment of the environmentally recruited, plant-

10 associated microbiota (the phytomicrobiome) and its functioning. This is no surprise considering that the

11 importance of the phytomicrobiome on plant health has only been demonstrated recently and that

12 phytomicrobiome composition is mainly determined by extrinsic factors (e.g. soil conditions, climate, culture

13 management practices; [3]), but also by intrinsic factors (e.g. vertical transfer through seeds, plant

14 characteristics, plant organs and plant-microbial interactions; [4-7])(Figure 1). Nonetheless, identifying the

15 driving-factors (e.g. keystone species, metabolites) explaining the assembly and composition of the

16 phytomicrobiome is still a challenge and a key question to understand the holobiont dynamic.

17 What is the role of symbionts? Although symbionts are members of the phytomicrobiome, are they intrinsic

18 or extrinsic drivers of phytomicrobiome composition and of the phytobiome? How do symbiont interactions and

19 the dynamic of their establishment impact the rules of assembly the phytomicrobiome? Symbionts strongly

20 modify plant ecophysiological traits, colonize part of the plant tissues and modify the local soil properties.

21 Furthermore, symbioses are known to modify plant signals (e.g. strigolactone), hormones (e.g. auxin), the

22 immune system (e.g. jasmonate signaling pathway) and exudates compositions (e.g. trehalose, glucosamine

23 derivatives). In this opinion paper, we describe how the molecular dialog between the symbionts shapes the

24 taxonomic and functional structures and the functioning of the phytomicrobiome, defining symbiotic organisms

25 as ecological engineers of the phytomicrobiome. To exemplify this concept, we have taken examples from the

26 best-documented symbioses, e.g. the endospheric symbioses, either mutualistic or detrimental, since they are the

27 only ones which impact on the phytomicrobiome has been tested experimentally.

29 Plant symbiont interactions: reprogramming the plant

$30 \quad$ What is symbiosis? 
1 Symbiosis means 'living together' and is understood here as all close and long term interactions between plants

2 and microorganisms. In symbiosis, interaction is the key notion. Symbionts exert influence on one another, and

3 express a reciprocal dialog, which eventually leads to modifications of the partners, but not necessarily. In this

4 view, the notion of symbiosis de facto excludes organisms which presence in the vicinity of the plant is due

5 solely to hazard and their spatial repartition in the environment, which display no interactions with the plant, in

6 the same way that a bird resting on a telegraph pole cannot be considered a symbiont of the pole, but a bird

7 nesting in, or feeding from, a tree could be. The most emblematic and ultimate symbioses remain the

8 (chloro)plasts and mitochondria, which correspond to long co-evolution processes between the eukaryotic cell

9 and symbiotic bacteria. Per se, symbioses are not necessarily beneficial to the host. Amongst plant-pathogen

10 relationships, the example of Agrobacterium tumefaciens, the causal agent of crown gall disease, is emblematic

11 of the fuzzy limits between beneficial and detrimental symbionts. Although this pathogen uses horizontal gene

12 transfer to engineer the plant and create its own ecological niche, this process usually only marginally impairs

13 plant growth. Numerous cases of beneficial plant symbiosis have been documented in depth such as the nitrogen-

14 fixing symbioses (e.g., Rhizobium/legumes) or the mutualistic association between mycorrhizal fungi (e.g.,

15 ectomycorrhizal (EM) and arbuscular mycorrhizal (AM) fungi and grass or trees).

17 How does symbiosis affect plant and symbiont partners?

18 From the plant perspective, interactions with symbionts modify intracellular and intercellular 19 communications, expression of hundred of genes (Box 1), and diversity and quantities of exudated metabolites $20[8,9]$, but also cell and tissue structure. These aspects have been described in depth for endospheric symbioses.

21 The modifications begin by an increase of intracellular calcium few seconds to minutes after the interaction with

22 symbionts. Formation of novel or mixed organs can be observed as in the nodules formed by Rhizobium or in the 23 mycorrhizal roots formed by symbiotic fungi. In these hybrid structures, the mycelium forms a specific network

24 in the apoplastic space, allowing for nutritive exchanges between the host plant and the fungus and some 25 metabolic reorientation, i.e. a decrease of starch and sucrose, and an increase of trehalose and mannitol 26 production, as well as an increase in respiration [10] or the accumulation of oxalate around mycorrhizal roots.

27 Metabolic reprogramming is also emblematic of the gall-forming A. tumefaciens infection which leads to the 28 production of Agrobacterium specific amino-acid derivatives, the opines, but also to a large remodeling of the 29 plant resource allocation (translocation of nutrients and water) to the benefit of the tumor, and the accumulation 
1 of dozen other carbon sources [11-13]. During the Rhizobium and Frankia infection, root cells are differentiated

2 to form nodules, in which low-oxygen and carbon rich conditions occur.

From the microbial side, cellular and genomic differentiation can occur. Upon induction of symbiosis, the

4 bacterial cell will undergo multiple rearrangements to create specialized cells. In plant root nodules, colonized by

5 nitrogen-fixing rhizobia, bacteria form immobile, larger cells with higher nitrogenase activity (i.e., the

6 bacteroids)[14]. Similarly, Frankia cells form larger cells with diazovesicles and nitrogenase activity [15].

7 During the plant/Agrobacterium interaction, no major morphological modifications occur, but the symbiosis

8 provokes genomic rearrangements of the microbial community via the dissemination of the pathogenic plasmids.

9 Last, obligate symbionts such as mitochondria, plasts and mollicutes for examples have both morphological and

10 extensive genomic optimizations.

11 In most cases, plants associated with symbionts such as mycorrhizal fungi or nodule forming rhizobacteria

12 present a higher biomass, hence the general terminology of plant growth promoting rhizobacteria (PGPR).

13 Medicago truncatula Nod'Myc $^{-}$mutants incapable of forming mycorrhizae and nodules, have a loss of biomass

14 that can reach up to $90 \%$ compared to the $\mathrm{Nod}^{+} \mathrm{Myc}^{+}$colonized plants [16]. Interestingly, the host-plants seem

15 capable of selecting the most effective symbionts, e.g. rhizobia with the higher nitrogenase activity, although the

16 effectiveness-driven selection remains to be confirmed [17,18]. Similarly, during the AM symbiosis, plant and

17 AM fungi set up a reciprocal " fair trade" [19], but this text book picture is highly variable and probably depends

18 on the plant species, the plant genotype and the AM fungal species [20,21].

19 In an evolutionary perspective, we are far from knowing all the cellular modifications induced during the

20 endosphere symbiotic association whether recent, such as mycorrhiza, or ancient, such as

21 mitochondria/chloroplasts. Our current knowledge points out at changes in hormone production (auxin,

22 strigolactone) and exudate composition, immune system adjustment (salicylate, jasmonate), volatiles, i.e. all

23 compounds potentially involved in the complex dialogue with the phytomicrobiome. The extent of modifications

24 in metabolite production induced during the Agrobacterium infection is a clear example that subtle modifications

25 in the metabolite or hormone balance can lead to important modifications of the metabolome and signalome of

26 the plant, and therefore of its interactome. In addition, the symbiosis establishment also yields modifications of

27 the physico-chemical properties of the soil (i.e., variation of $\mathrm{pH}$, higher content of $\mathrm{N}$ or trehalose, soil 28 aggregation...).

\section{Impact of symbiosis on the phytomicrobiome}


The possibility that plant endospheric symbionts may be keystone organisms capable of modifying their

2 environment (i.e., the phytobiome) has recently been predicted [22], but without experimental demonstration. In

3 nature, no symbiont-free plants exist. Hence, naturalistic approaches are ill suited to study the impact of the onset of symbiosis. However, experimental comparative analyses of plants impaired or not in their symbiotic capabilities, in presence or absence of symbionts or colonized by different symbionts can help decipher the relative role of endospheric symbionts on the phytomicrobiome and on the evolution of the holobiont.

What can we learn from plants impaired in their ability to form symbiosis?

One elegant way to observe the potential impact of symbionts on the phytomicrobiome is to use plants 10 impaired in their ability to associate with symbionts. To do so, several plants incapable of forming symbiotic 11 association with nodule and/or mycorrhizal forming symbionts are currently available (Glycine max, Lotus japonicus, Lycopersicon esculentum, M. trunculata, Nicotiana attenuata, Phaseolus vulgaris, Pisum sativum or

13 Vicia faba ; [23]). Only a few of these plants have been used to assay the impact of this phenotype on the 14 phytomicrobiome. Furthermore, these studies mainly focused on the taxonomic composition, e.g. the taxa in the 15 phytomicrobiome, or structure, e.g. the relative abundance of these taxa (Table 1). Amongst these, the most 16 extended study was performed in the M. truncatula Gaertn. cv. Jemalong line J5 (Wild type (WT), $\mathrm{Myc}^{+} \mathrm{Nod}^{+}$) 17 and its symbiosis-defective mutants TRV48 (Myc ${ }^{+} \mathrm{Nod}^{-}$; affected on the gene Mtsym15) and TRV25 (Myc-Nod; 18 affected on the gene DMI3). The monitoring of Medicago truncatula plants impaired in their ability to form one 19 or both nodule- or mycorrhizal symbioses showed a strong impact of the presence/absence of the symbiont(s) on 20 the taxonomic and functional structures of the phytomicrobiome $[16,24,25]$. These studies demonstrated that 21 both rhizosphere and endophytic microbiota were affected by the absence of the symbionts in the double Myc-

22 Nod- mutant, but this effect was not visible with the Myc+Nod- mutant, suggesting a differential impact of 23 nodule-forming symbiosis. Mycorrhizal plants were characterized by a preferential association with 24 Comamonadaceae, Oxalobacteraceae (i.e. Collimonas) and Rubrivivax and an enrichment of type III secretion 25 system (T3SS) carrying Pseudomonas in comparison to the non-mycorrhizal plants [25]. Similarly, the 26 monitoring of mutant lines of Lotus japonicus impaired at different stage of nodulation, showed that the level of 27 perturbation of nodulation did not impact the taxonomic structure and composition of the bacterial communities associated to the different mutant plants [26]. However, their phytomicrobiome differed significantly from that

29 of the WT (Table 1), which was attributed to symbiosis-related metabolic changes between the WT and mutant 30 genotypes as alternative drivers of phytomicrobiome differentiation [26]. Further work confirmed the stronger 
1 impact on the phytomicrobiome for mutant lines affected in their ability to establish both mycorrhizal and nodule 2 symbioses (http://dx.doi.org/10.1101/547687). While mycorrhization and nodulation seem to impact the 3 phytomicrobiome, the differences reported suggest that these two compartments (i.e., mycorrhizae and nodule)

4 do not impact the phytomicrobiome in the same way or intensity. These results demonstrate how the absence of

5 a single member of the phytomicrobiome (i.e., mycorrhizal symbiont) can strongly reshape the holobiont,

6 affecting both the composition and function of the phytomicrobiome and the plant growth. [25]. Interestingly,

7 the work done on $M$. truncatula suggests that mycorrhizal symbiosis has a stronger impact on the 8 phytomicrobiome than nodulation [16,24]. One may explain this difference by the fact that mycorrhizal fungi

9 exert a stronger influence on the surrounding plant environment through the direct effect of the fungal mantle 10 formed around the roots, which modifies soil properties and metabolites found around the roots, and 11 consequently the recruitment of bacteria by the hyphal network (e.g., fungal highway). Consistent with this view, 12 the functional characterization of the taxonomic groups enriched in fungal environments evidenced their ability 13 to hydrolyze chitin, utilize oxalate, glycerol or trehalose, or carry T3SS genes, abilities poorly encountered in 14 bulk soil bacterial communities [25,27]. Interestingly, the T3SS gene, usually associated with pathogenic 15 bacteria, was also found in non-pathogenic bacteria and was demonstrated to have a role in fungal interactions 16 and more especially in plant ectomycorrhizal or arbuscular mycorrhization [28,29]. A last important point is 17 related to the differences observed between the endophytic and rhizosphere microbiota in presence/absence of 18 the endospheric symbiont. While many studies reported an effect of the absence of the endospheric symbiont on

19 both the endophytic and rhizosphere microbiota (Table 1), it was not the case in others where only the 20 rhizosphere microbiota was affected [30], suggesting that subtle regulations drive differently the endophytic and 21 rhizosphere microbiota.

What can we learn from comparative analyses of natural and inoculated systems?

Another way to determine the impact of symbiosis on the phytomicrobiome is to analyze plants colonized by different symbionts species and capable of forming symbiosis with more than one type of symbiont, some to acquire nitrogen based on nodule forming bacteria, i.e., Rhizobium or Frankia, and some to acquire other inorganic nutrients, i.e., AM or EM fungi. While AM fungi are able to colonize root nodules in laboratory conditions, such colonization was rarely observed in situ. Considering different plants (Lotus, Trifolium and

29 Ononis) growing naturally in sand dunes, Scheublin et al. [31] reported that the AM fungal communities varied 
1 AM fungi and Rhizobium symbiosis prevents the later establishment of AM fungi [32]. Another one may be

2 related to the induction of plant defenses upon rhizobial infection, which blocks further AM fungal colonization.

3 Last, a priority effect may occur between the two symbionts determining community succession [33,34] on the

4 root system in $a$ 'first come, first served' basis. This is for example the case of Frankia and mycorrhizal fungi

5 that compete for the roots of Alnus trees. Actinorhizal nodules are formed prior to mycorrhizal fungi

6 establishment $[33,34]$. We observe that the community structure of EM fungi is function of the age of Alnus trees

7 [35], but also of the density of actinorhizal nodules on the root system. Leading to a variable primary symbiont

8 colonization, this competition subsequently leads to diverging phytomicrobiomes as evidenced in comparisons of

9 the phytomicrobiomes associated to the root system of the same plant, but colonized by different

10 ectomycorrhizal species [33-38]. For instance, young Pinus sylvestris seedlings grown in pots harbor specific

11 phytomicrobiomes according to the EM fungal species (i.e., roots associated to Russula sp., Piloderma spp.,

12 Meliniomyces variabilis and Paxillus involutus) which comprise common (i.e., Burkholderia) and EM species-

13 specific (i.e., Actinospica) bacterial genera [38]. Experiments based on controlled inoculation of plants

14 with/without a specific microorganism such as a symbiont or a mycorrhizal helper bacterial strains represent

15 another alternative to determine the relative effect of the presence of the symbiont on the plant microbiota

16 without the potential bias related to the genetic modification of the host-plant (Table 1). Similarly, we can

17 wonder if endophytes can affect the phytomicrobiome. Indeed, some of these endophytes are vertically

18 transferred, while others are acquired from the plant environment. Although most of them do not provoke

19 apparent cell differentiation in the plant, several studies pointed out their role in plant development and fitness

20 [39]. Comparing poplar inoculated or not with an endophyte (i.e., Mortierella elongate or Ilyonectria europaea),

21 Liao et al. [40] reported that plants, inoculated with the endophyte presented a better plant growth,

22 transcriptional changes in the poplar tissues and different compositions of their phytomicrobiome than non-

23 inoculated plants. Altogether, these comparisons highlight that the dynamic of colonization of the root system by

24 symbionts (even endophytes) is important and that the type of symbiont and/or the species strongly condition the

25 taxonomic composition, and thus the function, of the phytomicrobiome.

Agrobacterium tumor : a molecular demonstration of how a symbiosis impacts the phytomicrobiome

The Agrobacterium/plant interaction is a very interesting system in which the plant cellular factory is

29 reprogrammed to produce novel substrates, the opines [41], creating a specific ecological niche for the pathogen

30 (the opine concept, [42]). Plant cell reprogramming in the Agrobacterium tumor also implies a larger remodeling 
1 of the metabolome, with the increased production in the tumor of more than 20 other carbon compounds, such as

2 pyruvate, gluconate, which production is increased up to 5.10 times compared to the plant without tumor [43],

3 and the accumulation of signal molecules, plant hormones and bacterial signaling molecules, such as $\mathrm{N}-\mathrm{acyl}$

4 homoserine lactone produced by Agrobacterium, which diffuse in the surrounding environment of the plant and

5 may impact the surrounding phytomicrobiome. The short-circuiting of the cell results from the integration into

6 the plant genome of only a few genes for the synthesis of plant hormones, which leads to an unlimited growth of

7 the plant cell, and for the production of the novel substrates. Interestingly, as this symbiosis is based on gene

8 transfer into the genome of the plant but not on the pathogen itself, it can be easily manipulated to generate

9 axenic plants to assay the impact of Agrobacterium-induced plant reprogramming on the phytomicrobiome.

10 Opines give a fitness advantage in vitro and in vivo to the bacteria capable of metabolizing these molecules [44].

11 One can observe a clear reshaping of the phytomicrobiome whichever opine is used [44-46]. The modifications

12 impact the community composition, but moreover its functional structure, since specific microorganisms are

13 selected and increase significantly in proportion $[44,46]$. These correspond only in part to bacteria able to utilize

14 opines newly produced by the plants. In the field, the microbiome of the crown gall tumor also differs

15 significantly from that of the healthy plant in both composition, richness and dynamics [47]. Thus, by directly

16 and indirectly modifying the capacity of the plant cell to produce carbon molecules and to secrete them in the

17 extracellular space, this endospheric interaction perfectly illustrates the possibility that exists during the

18 establishment of a symbiosis (here a detrimental symbiosis) to reshape the phytomicrobiome, through the

19 modification of plant signals and/or reprogramming of cell exudates. This cascade of effects in the plant and the

20 symbiont is what we termed the 'symbiotic cascade effects' (Box2), in which the symbiont through its direct and

21 indirect effects on the plant reshapes the phytomicrobiome. Of course, the mechanisms involved (gene

22 regulation, metabolites, signals) may strongly differ from a symbiont to another or depending of the host-plant.

23 Whether and how, this is controlled by, or affects, the plant health in fine is still an open question.

\section{Concluding remarks and future perspectives:}

For decades, the ability of plants to grow and adapt to extreme and dynamic conditions has been linked to

27 their functional versatility. Today, it is obvious that it largely depends on their ability to establish interactions

28 (sometimes symbiotic) with specific bacteria and/or fungi recruited from their environment or vertically

29 transferred (e.g., from the seeds), and possibly archaea and on the interactions between microorganisms [62].

30 Here, we propose a new paradigm that we termed the 'symbiotic cascade effects', which proposes to consider 
1 not only the plant and its environment as engineers of the phytomicrobiome, but also members of the

2 phytomicrobiome such as the symbionts (Box 2, Table 1). Recent findings suggest that these symbiotic cascade

3 effects may be extended to other microorganisms such as endophytes [40]. Modifications of the plant microbiota

4 can be due to a direct action of the symbionts, through a priority effect, a competition for the same ecological

5 niche or through the production of signal molecules, new metabolites or the modulation of plant signaling. The

6 priority effect, e.g. the sequential arrival of microbial populations in the vicinity of the root system, is a strong

7 driver of phytomicrobiome structuration and composition which has been demonstrated in several plant systems.

8 However, it is also clear that a plant impaired in its ability to form a symbiosis does not react in the same way to

9 the presence of bacteria in its vicinity. This is already visible in the plant transcriptomic response of the plant

10 which expresses several genes of the signal transduction pathway in the WT, but only one in the Myc-Nod $^{-}$

11 mutants [48], suggesting an attenuation of the reaction of the plant when symbionts are absents. This observation

12 has strong implications on our understanding of the holobiont, as it means that the presence/absence of a

13 symbiont conditions the holobiont. Similarly, mycorrhizal establishment is known to modify the balance of

14 immune molecules. In this view, jasmonic acid (JA) is strongly suspected to be a key molecule driving the

15 selection of the phytomicrobiome [49-52]. Indeed, while JA addition in soil microcosms planted with

16 Arabidopsis thaliana significantly impacts the rhizosphere communities, no effect is observed on those from the

17 surrounding bulk soil. JA, salicylate, or nitrite oxide also induce important modifications of the metabolites

18 exudated in the rhizosphere of plants, with the presence of specific substrates such as for example kaempferol-3-

19 O- $\beta$-d-glucopyranoside-7-O- $\alpha-1-$ rhamnoside [49]. Beside JA, many other signals and metabolites produced

20 during microbe-microbe or microbes-plants interactions may be involved in the symbiotic cascade effect [48].

21 Their identity and their relative role remain to be determined. Last, the impact of symbionts on the

22 phytomicrobiome can also be indirect through environmental changes. Indeed, mycorrhizal fungi are known to

23 increase soil aggregation around roots allowing for a better stability of the soil matrix and physico-chemical

24 changes (e.g. resource depletion), while nodules are known to enrich the surrounding bulk soil in nitrogen. Based

25 on the experiments done with plants impaired in their ability to form symbiosis compared to their wild-type

26 relatives, we know that a complex cascade of events occurs allowing for modifications of the taxonomic and

27 functional structures of the phytomicrobiome. The question is now to identify the mechanisms by which these

28 modifications are driven (see Outstanding questions). The demonstration provided here is mainly focused on the

29 effect on the phytomicrobiome of endosphere symbionts colonizing the root system because they are the only

30 systems for which some data exists. However, during the establishment of any microbial community at the plant/ 
1 environment interface a molecular dialog will take place between the plant and the new comers. The depth of the

2 dialog will depend on the type of organisms, but also on the duration of the interaction (i.e., short or long term).

3 This dialogue will trigger modifications in the plant and/or the phytomicrobiome, which in turn will potentially

4 impact the relationships of the plant with its phytomicrobiome. Whatever the symbiont and the plant

5 compartment, more studies combining environmental genomics and microbiology, plant physiology,

6 metabolomics are required to progress in this direction. Progressing in this field would permit to open new

7 perspectives in the prediction and engineering of the phytomicrobiome and its performances.

\section{Acknowledgements}

10 This work was supported by the French Agency through the Laboratory of Excellence Arbre (ANR-11-LABX-

11 0002-01) and by the division of Plant Health and Environment of the French National Institute for Agricultural

12 Research (INRA). We thank Drs F. Martin and C. Veneault-Fourrey for helpful discussions.

\section{References:}

15 1. Shropshire, J.D. and Bordenstein, S.R. (2016) Speciation by symbiosis: the microbiome and behavior. MBio 7 , $16 \mathrm{e} 01785-15$.

17 2. Vandenkoornhuyse, P. et al. (2015) The importance of the microbiome of the plant holobiont. New Phytol. $18 \quad 206,1196-1206$.

19 3. Lundberg, D.S. et al. (2012) Defining the core Arabidopsis thaliana root microbiome. Nature $488,86$.

20 4. Chaparro, J.M. et al. (2014) Rhizosphere microbiome assemblage is affected by plant development. The ISME $21 J .8,790$.

22 5. Colin, Y. et al. (2017) Taxonomic and functional shifts in the beech rhizosphere microbiome across a natural

23 soil toposequence. Sci. Rep. UK 7, 9604.

24 6. Haichar, F. et al. (2016) Stable isotope probing of carbon flow in the plant holobiont. Cur. Opin. Biotech. 41, $259-13$

26 7. Marschner, P. et al. (2001) Soil and plant specific effects on bacterial community composition in the 27 rhizosphere. Soil Biol. Biochem. 33, 1437-1445.

28 8. Jones, D.L. et al. (2004) Plant and mycorrhizal regulation of rhizodeposition. New Phytol. 163, 459-480.

29 9. Wong, J.W.H. et al. (2019) The influence of contrasting microbial lifestyles on the pre-symbiotic metabolite

30 responses of Eucalyptus grandis roots. Front. Ecol. Evol. 7, 10. 
1 10. Douds, D.D. et al. (2000) Carbon partitioning, cost and metabolism of Arbuscular Mycorrhizae. In: Douds

2 DD, Kapulnik Y, editors. Arbuscular Mycorrizas Physiology and Function. Dordrecht, The Netherlands: Kluwer

3 Academic Publishers; pp. 107-130.

4 11. Deeken, R. et al. (2006) An integrated view of gene expression and solute profiles of Arabidopsis tumours: a

5 genome-wide approach. Plant Cell 18, 3617-3634.

6 12. Gohlke, J. and Deeken, R. (2014) Plant responses to Agrobacterium tumefaciens and crown gall

7 development. Front. Plant Sci. 5, 155.

8 13. Gonzalez-Mula, A. et al. (2018) The biotroph Agrobacterium tumefaciens thrives in tumors by exploiting a

9 wide spectrum of plant host metabolites. New Phytol. DOI: 10.1111/nph.15598

10 14. Oke, V. and Long, S.R. (1999) Bacteroid formation in the Rhizobium-legume symbiosis. Cur. Opin.

11 Microbiol. 2, 641-646.

12 15. Huss-Danell, K. and Bergman, B. (1990) Nitrogenase in Frankia from root nodules of Alnus incana (L.)

13 Moench: immunolocalization of the Fe-and MoFe-proteins during vesicle differentiation. New Phytol. 116, 443-

14455.

15 16. Offre, P. et al. (2007) Identification of bacterial groups preferentially associated with mycorrhizal roots of

16 Medicago truncatula. Appl. Environ. Microb. 73, 913-921.

17 17. Kiers, E.T. et al. (2003) Host sanctions and the legume-rhizobium mutualism. Nature 425, 78-81.

18 18. Bourion, V. et al. (2018) Co-inoculation of a pea core-collection with diverse rhizobial strains shows 19 competitiveness for nodulation and efficiency of nitrogen fixation are distinct traits in the interaction. Front.

20 Plant Sci. 8, 2249.

21 19. Kiers, E.T. et al. (2011) Reciprocal rewards stabilize cooperation in the mycorrhizal symbiosis. Science 333,

$22880-882$.

23 20. Walder, F. et al. (2012) Mycorrhizal networks: common goods of plants shared under unequal terms of trade.

24 Plant Physiol. 159: 789-797.

25 21. Wipf, D. et al. (2019) Trading on the arbuscular mycorrhiza market: from arbuscules to common 26 mycorrhizal networks. New Phytol. in press

27 22. Banerjee, S., Schlaeppi, K., \& Heijden, M. G. (2018). Keystone taxa as drivers of microbiome structure and 28 functioning. Nature Rev. Microbiol., 1.

29 23. Duc, G. and Messager, A. (1989) Mutagenesis of pea (Pisum sativum L.) and the isolation of mutants for 30 nodulation and nitrogen fixation. Plant Sci. 60, 207-213. 
1 24. Offre, P. et al. (2008) Microdiversity of Burkholderiales associated with mycorrhizal and nonmycorrhizal 2 roots of Medicago truncatula. FEMS Microbiol. Ecol. 65, 180-192.

3 25. Viollet, A. et al. (2011) Fluorescent pseudomonads harboring type III secretion genes are enriched in the 4 mycorrhizosphere of Medicago truncatula. FEMS Microbiol. Ecol. 75, 457-467.

5 26. Zgadzaj, R. et al. (2016) Root nodule symbiosis in Lotus japonicus drives the establishment of distinctive

6 rhizosphere, root, and nodule bacterial communities. P. Natl. Acad. Sci. USA 113, 7996-8005.

7 27. Leveau, J.H. et al. (2010) The bacterial genus Collimonas: mycophagy, weathering and other adaptive 8 solutions to life in oligotrophic soil environments. Environ. Microbiol. 12, 281-292.

9 28. Cusano, A.M. et al. (2011) Pseudomonas fluorescens BBc6R8 type III secretion mutants no longer promote 10 ectomycorrhizal symbiosis. Environ. Microb. Rep. 3, 203-210.

11 29. Viollet, A. et al. (2017) Pseudomonas fluorescens C7R12 type III secretion system impacts mycorrhization 12 of Medicago truncatula and associated microbial communities. Mycorrhiza 2, 23-33.

13 30. Ikeda, S. et al. (2008) Microbial community analysis of field-grown soybeans with different nodulation 14 phenotypes. Appl. Environ. Microbiol. 74, 5704-5709.

15 31. Scheublin, T.R. et al. (2004) Nonlegumes, legumes, and root nodules harbor different arbuscular mycorrhizal 16 fungal communities. Appl. Environ. Microb. 70, 6240-6246.

17 32. Martin, F.M. et al. (2017) Ancestral alliances: plant mutualistic symbioses with fungi and bacteria. Science $18356,4501$.

19 33. Miller, S.L. et al. (1992) Early colonization of red alder and Douglas fir by ectomycorrhizal fungi and

20 Frankia in soils from the Oregon coast range. Mycorrhiza 2, 53-61.

21 34. Kennedy, P.G., Peay, K.G., \& Bruns, T.D. (2009). Root tip competition among ectomycorrhizal fungi: are 22 priority effects a rule or an exception? Ecology, 90, 2098-2107.

23 35. Schwob, G. et al. (2017) Green alder (Alnus viridis) encroachment shapes microbial communities in

24 subalpine soils and impacts its bacterial or fungal symbionts differently. Environ. Microbiol. 19, 3235-3250.

25 36. Izumi, H. and Finlay, R.D. (2011) Ectomycorrhizal roots select distinctive bacterial and ascomycete 26 communities in Swedish subarctic forests. Environ. Microbiol. 13, 819-830.

27 37. Uroz, S. et al. (2012) Distinct ectomycorrhizospheres share similar bacterial communities as revealed by 28 pyrosequencing-based analysis of 16S rRNA genes. Appl. Environ. Microb. 78, 3020-3024. 
1 38. Marupakula, S. et al. (2016) Analysis of single root tip microbiomes suggests that distinctive bacterial

2 communities are selected by Pinus sylvestris roots colonized by different ectomycorrhizal fungi. Environ.

3 Microbiol. 18, 1470-1483.

4 39. Rodriguez, R.J., White Jr, J.F., Arnold, A.E., \& Redman, A.R.A. (2009). Fungal endophytes: diversity and

5 functional roles. New phytologist, 182, 314-330.

6 40. Liao, H.L., et al. (2019). Fungal endophytes of Populus trichocarpa alter host phenotype, gene expression

7 and rhizobiome composition. Mol. Plant-Microbe Interact.(ja).

8 41. Hooykaas, P.J. and Schilperoort, R.A. (1992) Agrobacterium and plant genetic engineering. Plant Mol. Biol.

9 19, 15-38.

10 42. Tempé, J. et al. (1979) In, Timmis KN, Puhler A. (eds) Plasmids of medical, commercial and environmental

11 importance, pp. 353-363. Elsevier/North Holland Biomedical Press, Amsterdam

12 43. Gonzalez-Mula, A. et al. (2018) The biotroph Agrobacterium tumefaciens thrives in tumors by exploiting a

13 wide spectrum of plant host metabolites. New Phytologist. https://doi.org/10.1111/nph.15598

14 44. Oger, P.M. et al. (1997) Genetically engineered plants producing opines alter their biological environment.

15 Nature Biotech. 15, 369.

16 45. Oger, P.M. et al. (2004) Engineering root exudation of Lotus toward the production of two novel carbon

17 compounds leads to the selection of distinct microbial populations in the rhizosphere. Microb. Ecol. 47, 96-103.

18 46. Mondy, S. et al. (2014) An increasing opine carbon bias in artificial exudation systems and genetically

19 modified plant rhizospheres leads to an increasing reshaping of bacterial populations. Mol. Ecol. 23, 4846-4861.

20 47. Faist, H. et al. (2016) Grapevine (Vitis vinifera) crown galls host distinct microbiota. Appl. Environ.

21 Microbiol. 82, 5542-5552.

22 48. Sanchez, L. et al. (2005) Pseudomonas fluorescens and Glomus mosseae trigger DMI3-dependent activation

23 of genes related to a signal transduction pathway in roots of Medicago truncatula. Plant Physiol. 139, 1065-

241077

25 49. Carvalhais, L.C. et al. (2017) Jasmonic acid signalling and the plant holobiont. Cur. Opin. Microbiol. 37, 422647.

27 50. Carvalhais, L.C. et al. (2015) Linking jasmonic acid signaling, root exudates, and rhizosphere microbiomes.

28 Mol. Plant-Microb. Interact. 28, 1049-1058.

29 51. Carvalhais, L.C. et al. (2013) Activation of the jasmonic acid plant defence pathway alters the composition

30 of rhizosphere bacterial communities. PLoS One 8, e56457. 
1 52. Leach, J.E. et al. (2017). Communication in the phytobiome. Cell, 169, 587-596.

2 53. Plett, J.M. et al. (2015) The mutualist Laccaria bicolor expresses a core gene regulon during the colonization

3 of diverse host plants and a variable regulon to counteract host-specific defenses. Mol. Plant Microbe In. 28, $4 \quad 261-273$

5 54. Hacquard, S. et al. (2013) Laser Microdissection and microarray analysis of Tuber melanosporum 6 ectomycorrhizas reveal functional heterogeneity between mantle and Hartig net compartments. Environ.

7 Microbiol. 15, 1853-1869.

8 55. Lévy, J. et al. (2004) A putative Ca2+ and calmodulin-dependant protein kinase required for bacteria and

9 fungal symbiosis. Science 303, 1361-1364.

10 56. Mitra, R.M. et al. (2004) A $\mathrm{Ca}^{2+} /$ calmodulin-dependant protein kinase required for symbiotic nodule

11 development: gene identification by transcript-based cloning. P. Natl. Acad. Sci. USA 101, 4701-4705.

12 57. Oldroy, G.E.D. (2013) Speak, friend, and enter: signaling systems that promote beneficial symbiotic

13 associations in plants. Nat. Microb. 11, 252-263.

14 58. Rich, M. et al. (2017) Diet of arbuscular mycorrhizal fungi: bread or butter? Trends Plant Sci. 22, 652-660.

15 59. Ried, M.K. et al. (2014) Spontaneous symbiotic reprogramming plant roots triggered by receptor-like 16 kinases. eLife 3, e03891.

17 60. Camps, C. et al. (2015) Combined genetic and transcriptomic analysis reveals three major signalling 18 pathways activated by Myc-LCOs in Medicago truncatula. New Phytol. 208, 224-240.

19 61. Pimprikar, P. and Gutjahr, C. (2018) Transcriptional regulation of arbuscular mycorrhiza development. Plant 20 Cell Physiol. 59, 678-695.

21 62. Hassani, M.A. et al. (2018) Microbial interactions within the plant holobiont. Microbiome 6, 58.

22 63. Groten, K. et al. (2015) Silencing a key gene of the common symbiosis pathway in Nicotiana attenuata

23 specifically impairs arbuscular mycorrhizal infection without influencing the root-associated microbiome or 24 plant growth. Plant Cell Environ. 38, 2398-2416.

25 64. Ikeda, S. et al. (2011) The genotype of the calcium/calmodulin-dependent protein kinase gene (CCaMK) 26 determines bacterial community diversity in rice roots under paddy and upland field conditions. Appl. Environ.

27 Microb. 77, 4399-4405.

28 65. Bao, Z. et al. (2014) A rice gene for microbial symbiosis, OsCCaMK, reduces CH4 flux in a paddy field with

29 low nitrogen input. Appl. Environ. Microb. 80, 1995-2003. 
1 66. Okubo, T. et al. (2009) Nodulation-dependent communities of culturable bacterial endophytes from stems of

2 field-grown soybeans. Microb. Environ. 24, 253-258.

3 67. Zhang, F. et al. (2019) Trichoderma-Inoculation and mowing synergistically altered soil available nutrients,

4 rhizosphere chemical compounds and soil microbial community, potentially driving alfalfa growth. Front.

$5 \quad$ Microbiol. 9: 3241.

6 68. Zhong, Y. et al. (2019) Genotype and rhizobium inoculation modulate the assembly of soybean

7 rhizobacterial communities. Plant Cell Env. DOI : 10.1111/pce.13519

8 69. Rodríguez-Caballero, G. et al. (2017) Arbuscular mycorrhizal fungi inoculation mediated changes in

9 rhizosphere bacterial community structure while promoting revegetation in a semiarid ecosystem. Sci. Total

10 Environ. 584, 838-848.

11 70. Lu, J. et al. (2017) Co-existence of Rhizobia and diverse non-rhizobial bacteria in the rhizosphere and 12 nodules of Dalbergia odorifera seedlings inoculated with Bradyrhizobium elkanii, Rhizobium multihospitium-

13 like and Burkholderia pyrrocinia-like strains. Front. Microbiol. 8, 2255.

14 71. Marschner, P. and Baumann, K. (2003) Changes in bacterial community structure induced by mycorrhizal 15 colonisation in split-root maize. Plant Soil 251, 279-289.

16 72. Fan, M. et al. (2018) Enhanced phytoremediation of Robinia pseudoacacia in heavy metal-contaminated

17 soils with rhizobia and the associated bacterial community structure and function. Chemosphere 197, 729-740.

18 73. Theis, K.R., Dheilly, N.M., Klassen, J.L., Brucker, R.M., Baines, J.F., Bosch, T.C., ... \& Sapp, J. (2016).

19 Getting the hologenome concept right: an eco-evolutionary framework for hosts and their microbiomes. mSys-

20 tems, $1, \mathrm{e} 00028-16$. 
3 Figure 1: Known or suspected environmental drivers of the taxonomic and functional structures of the

4 phytomicrobiome. Here are presented the different environmental filters (and the related factors) highly

5 suspected to drive the structuration of the plant-associated microbiota. The last filter presented corresponds to

6 the symbiont effect discussed in this manuscript. The different forms visible represents different microorganisms

7 which composition is modified by the different filters and at each step from the top to the bottom.

8

\section{FILTERS}

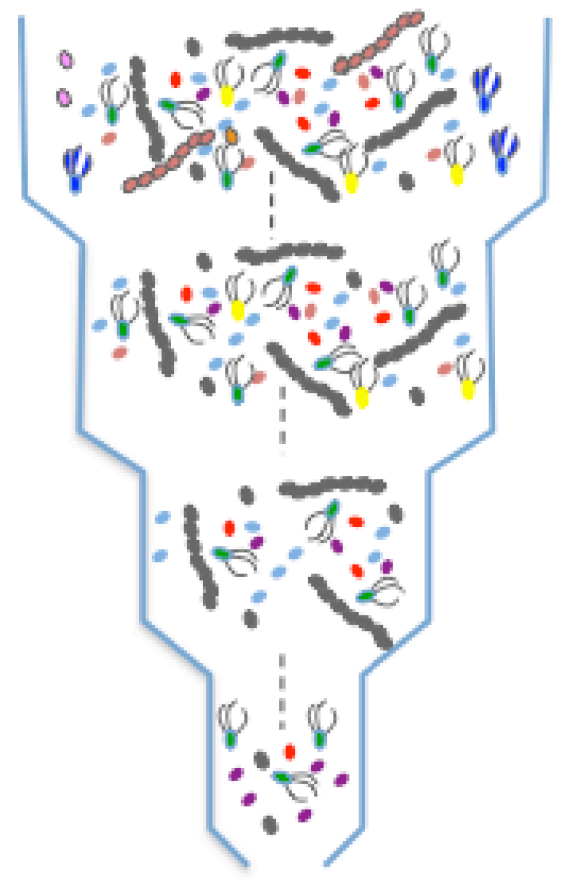

Climate (Temperature, rainfall)

Soil ( $\mathrm{pH}$, water, texture)

Plant (Exudates, signals and

soil modifications induced by the plant)

Symbiot (Exudates, signals and soil modifications) 


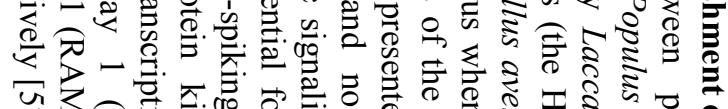
पy

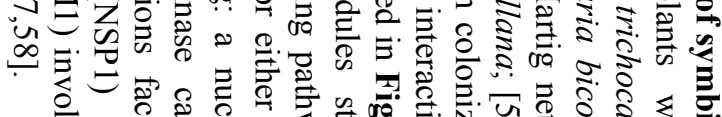

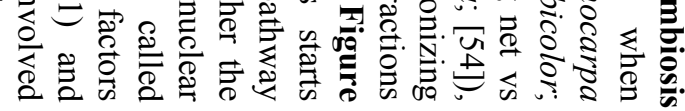

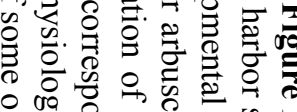

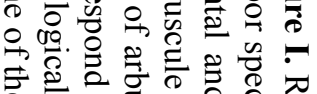

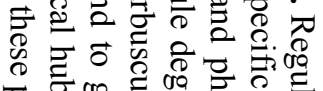

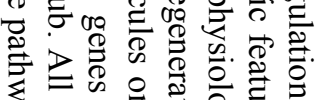

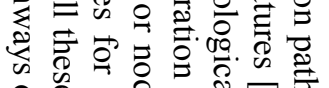
o

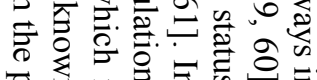

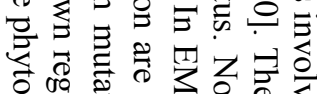

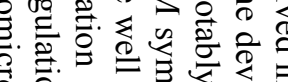

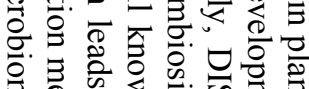

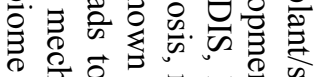

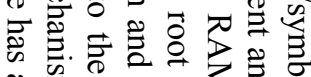

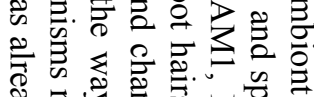

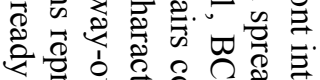

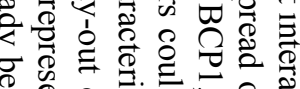

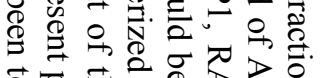

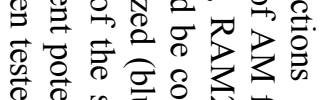

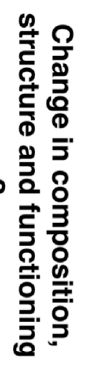

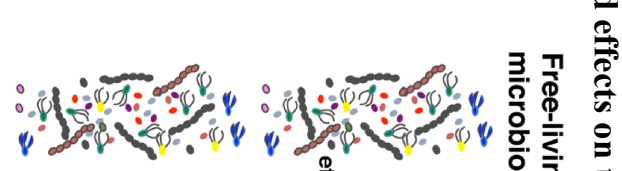

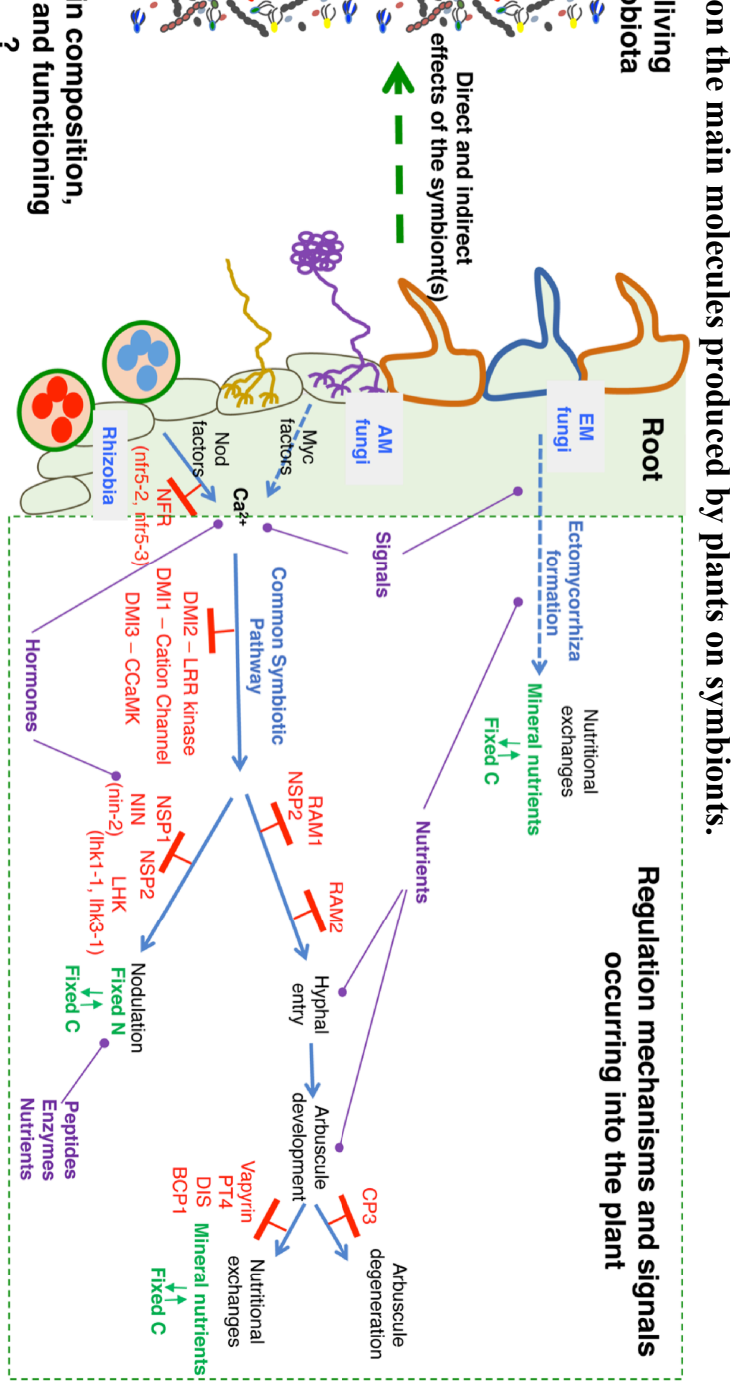


1 Box 2: The 'symbiotic cascade effects' or how symbiont establishment affects and drives the 2 phytomicrobiome.

3 Here, we present the cascade of events, which allows the structuration of the plant-associated microbiome. At

4 each of the different steps of the plant-symbiont interaction, the microbiota can be impacted. 1) As soon as 5 symbionts interact with the host-plant (i.e., at the pre-symbiotic stage or at the seed germination stage for seed

6 endophytes) through signal molecules and physical contact, physiological changes are induced in the plant and

7 competition occur for the plant tissues with the free-living microbiota. 2) During symbiont establishment, the

8 physiological changes in the plant are amplified and structural changes can appear (i.e., nodule or mycorrhiza

9 formation). 3) During symbiosis, the metabolites (carbohydrates, hormones, signals, volatiles) produced by the

10 plant and potentially exudated are modified quantitatively and/or qualitatively (i.e., new metabolites are

11 produced due to the symbiont) as well as the plant defense response. 4) The impact of the plant on the soil

12 parameters differs from the plant non-associated to symbionts. All these modifications impact the taxonomic and

13 functional structuration of the phytomicrobiome as well as its functioning, and in fine the plant fitness.

15 Table I: Main molecules produced by the plant with and without symbionts, which could drive modifications of the phytomicrobiome. The table is a non-exhaustive list of metabolites involved in the

17 structuration of the phytobiome by the host-plant and/or the symbionts. Here, we mainly listed the metabolites 18 produced only in presence of the symbionts or which concentrations change notably.

19

\begin{tabular}{|c|c|c|c|}
\hline $\begin{array}{c}\text { Molecule } \\
\text { type }\end{array}$ & $\begin{array}{c}\text { EM and AM } \\
\text { molecules }\end{array}$ & $\begin{array}{c}\text { Nodule } \\
\text { molecules }\end{array}$ & $\begin{array}{c}\text { Crown gall } \\
\text { molecules }\end{array}$ \\
\hline $\begin{array}{l}\text { Nutrients } \\
\text { (carbohydrates, } \\
\text { amino acids and } \\
\text { derivatives) }\end{array}$ & $\begin{array}{l}\text { Trehalose } \\
\text { Mannitol } \\
\text { Chitin and } \\
\text { derivatives }\end{array}$ & Nitrogen & $\begin{array}{l}\text { Opines } \\
\text { Proline } \\
\text { 3-caffeoylquinate } \\
\text { glucosinolate-2 } \\
\text { Pipecolate } \\
\text { Pyruvate } \\
\text { Dopamine } \\
\text { Salicylate } \\
\text { Calystegine B4 }\end{array}$ \\
\hline
\end{tabular}




\begin{tabular}{|c|c|c|c|}
\hline & & & $\begin{array}{l}\text { Nicotinate } \\
\text { Ferulate-trans } \\
\text { Gulonate } \\
\text { 4-hydroxyproline } \\
\text { Nicotianamine } \\
\text { Melezitose } \\
\text { Spermidine } \\
\text { Lactobionate }\end{array}$ \\
\hline Signals & $\begin{array}{l}\text { Calcium, ethylene } \\
\text { Jasmonate } \\
\text { Sesquiterpene }\end{array}$ & Flavoinoids, Phenolic acids & - Acyl homoserine lactone (AHL) \\
\hline Hormones & $\begin{array}{l}\text { Hypaphorin } \\
\text { (Tryptophan betain) }\end{array}$ & & \\
\hline Peptides & $\begin{array}{l}\text { Mycorrhizal } \\
\text { induced secreted } \\
\text { proteins (MISP) }\end{array}$ & $\begin{array}{l}\text { Nodule specific cysteine } \\
\text { rich } \\
\text { Rhizobial factors }\end{array}$ & \\
\hline Enzyme & & $\begin{array}{l}\text { 1-aminocyclopropane-1- } \\
\text { carboxylate } \\
\text { deaminase }(a c d S)\end{array}$ & \\
\hline
\end{tabular}

1

2

3

4

5

6 


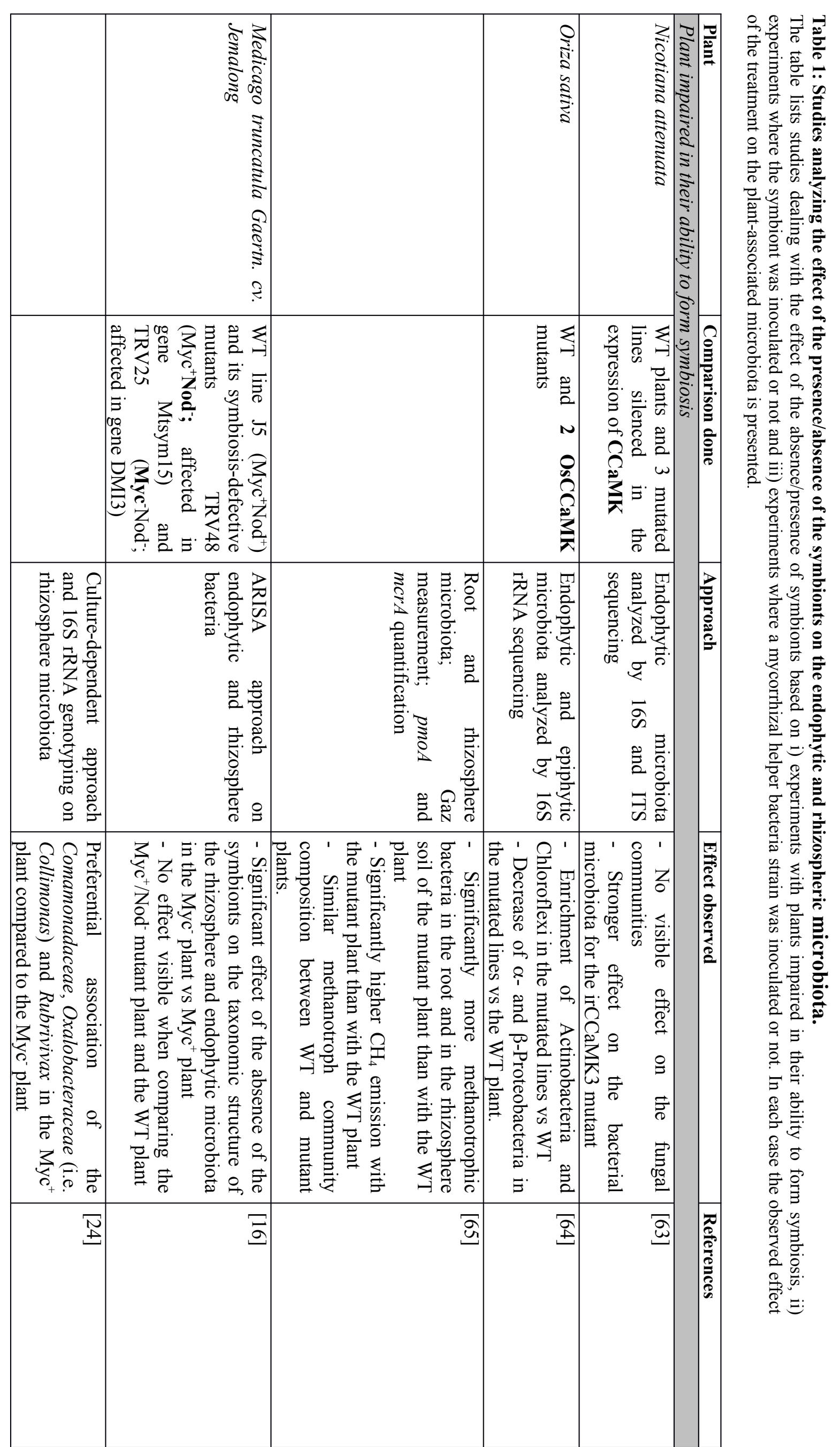




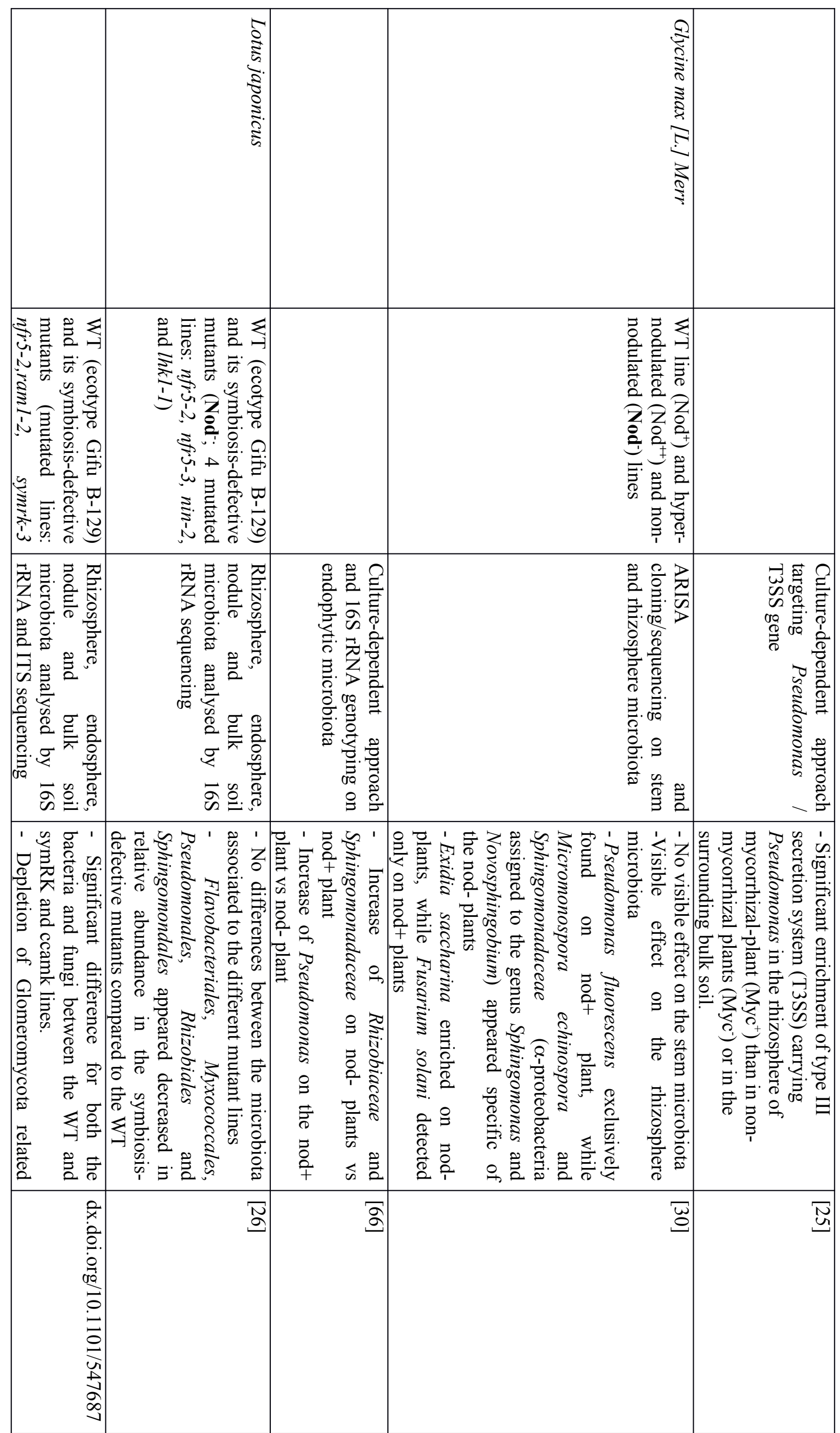




\begin{tabular}{|c|c|c|c|c|c|c|}
\hline $\begin{array}{c}\overrightarrow{0} \\
0 \\
\vdots \\
\vdots \\
0 \\
0 \\
0 \\
0 \\
0 \\
0 \\
0 \\
0 \\
\vdots\end{array}$ & 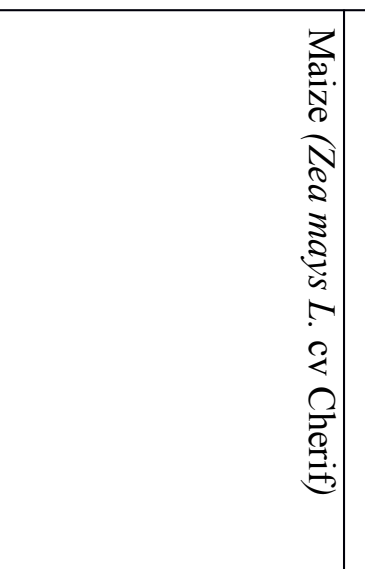 & 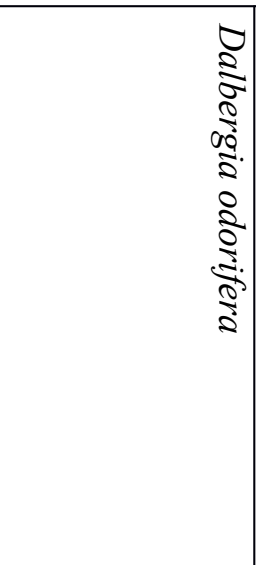 & 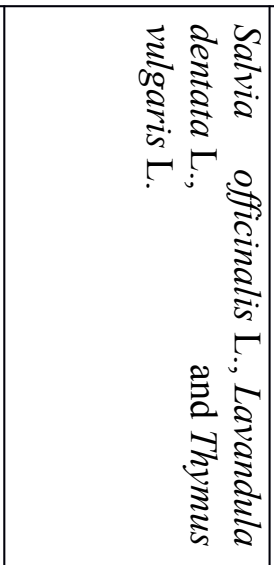 & \begin{tabular}{l|}
$\mid \tilde{y}$ \\
$\vdots$ \\
$\vdots$ \\
$\vdots$ \\
$\vdots$
\end{tabular} & 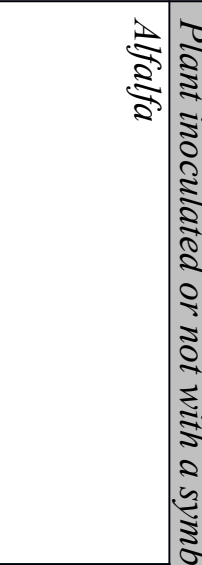 & \\
\hline 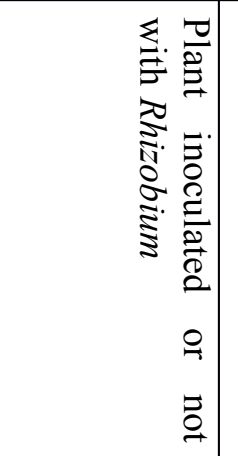 & 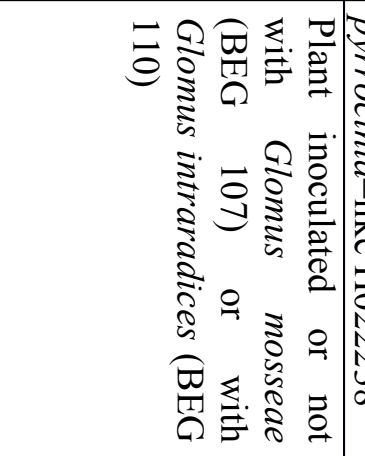 & 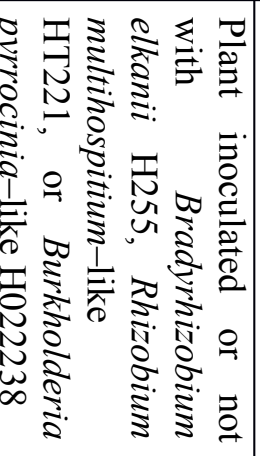 & 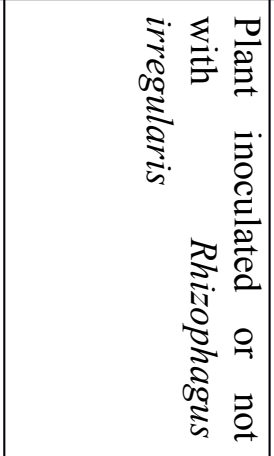 & 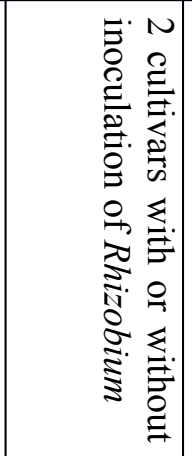 & 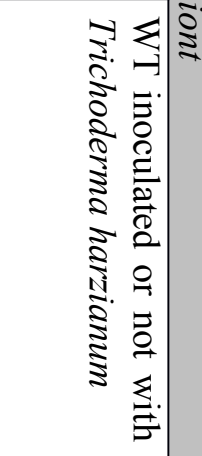 & \\
\hline 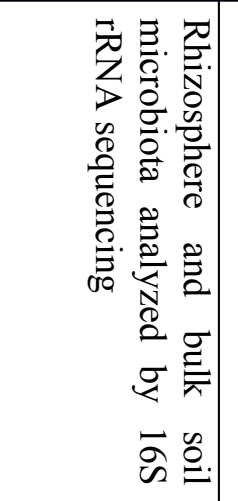 & 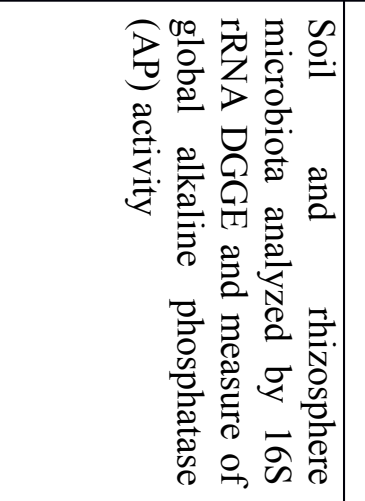 & 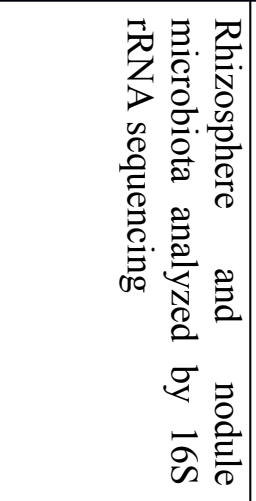 & 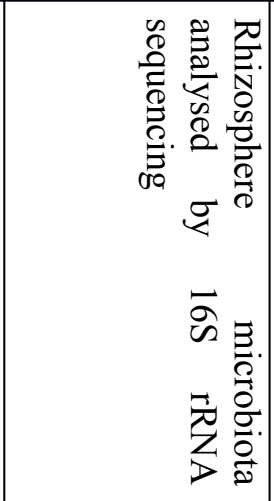 & 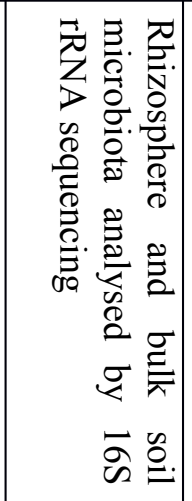 & 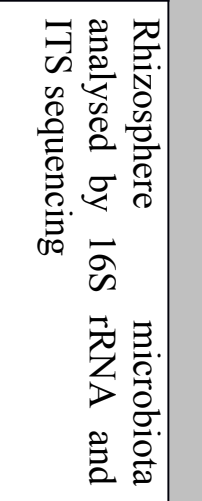 & \\
\hline 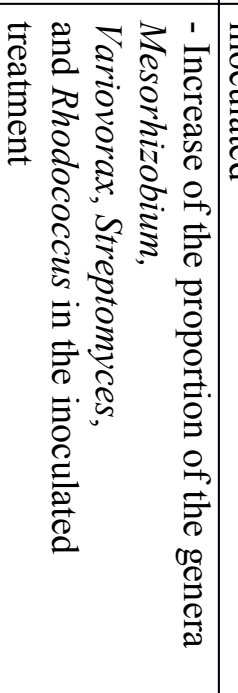 & 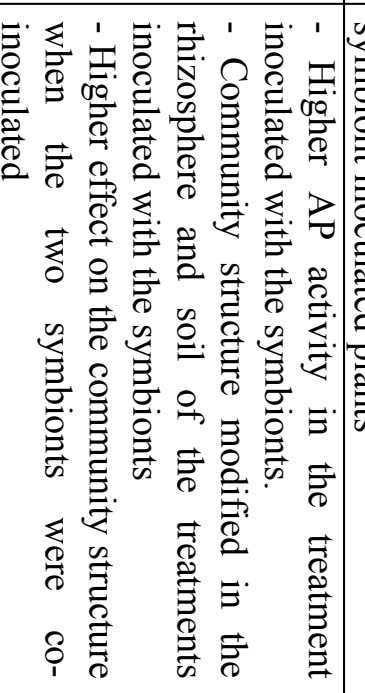 & 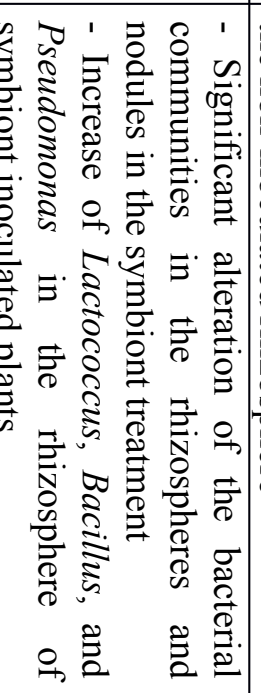 & 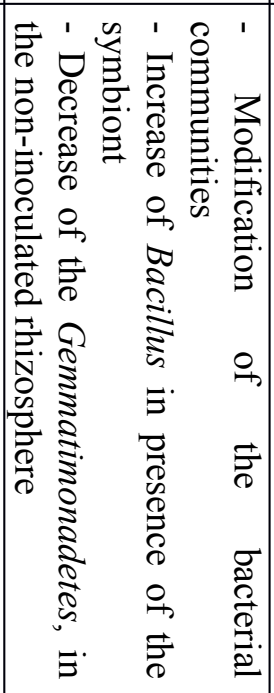 & 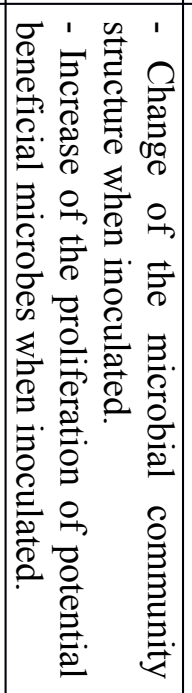 & 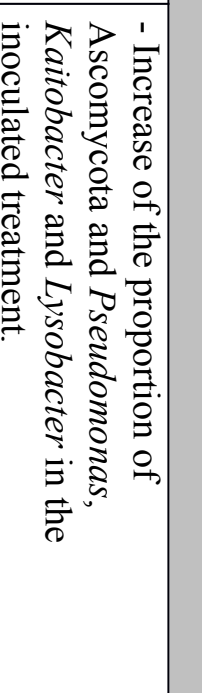 & 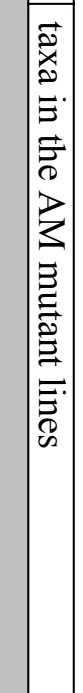 \\
\hline$\Xi$ & $\bar{\Xi}$ & $\vec{s}$ & $\overline{\mathrm{a}}$ & $\overline{\widehat{\alpha}}$ & $\overline{3}$ & \\
\hline
\end{tabular}




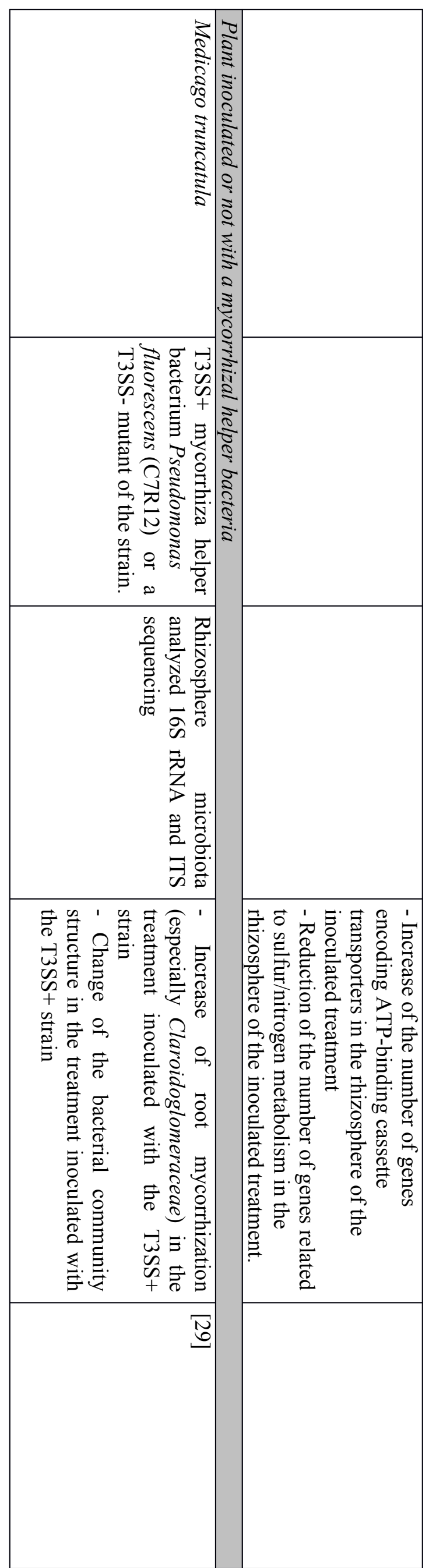




\section{GLOSSARY :}

2 Arbuscular mycorrhiza: from myco, fungus; and rhiza, root, the symbiotic association between roots of $85 \%$ of

3 land plants and fungi belonging to the Glomeromycota division. Symbiotic fungi that penetrate inside the

4 cortical cells of the root and form arbuscules, the 'tree-like' fungal structure developing within plant cortical

5 cells in arbuscular mycorrhizal symbiosis.

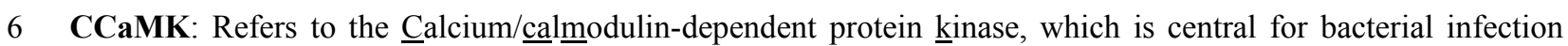

7 and nodule organogenesis as well as for arbuscular mycorrhizal symbiosis.

8 Crown gall: Disease provoked by Agrobacterium tumefaciens which is characterized by tumoral growth. Along

9 with the hairy root disease, crown gall is the only known example of natural genetic transformation which

10 development allowed the creation of genetically engineered plants.

11 Ectomycorrhiza : the symbiotic association between roots from trees and shrubs and fungi belonging to the

12 Ascomycota and Basidiomycota phyla. Fungi form a symbiotic interface encompassing plant cortical cells in

13 ectomycorrhizal symbiosis. Described for the first time by Robert Hartig and termed as the Hartig network.

14 Endophyte: Microorganisms residing in the plant tissues.

15 Endosphere: Internal regions of plant tissues that can be colonized by microorganisms.

16 Endospheric symbiosis: Refer to a symbiotic association where the symbiont colonizes the inside of the plant

17 (i.e., the endosphere). This term is to oppose to exosymbiosis, which corresponds to a symbiotic association,

18 where the symbiont does not colonize the plant tissues.

19 Extrinsic factors: Factors related to the environment

20 Functioning: In complex assembly systems (e.g., microbial communities and/or plant-microbe interaction) this

21 term refers to the global phenotype observed, which results from the relative sum of all the functions of the

22 members of this complex assembly.

23 Holobiont: Assemblage of different species that form an ecological unit (see ref. [73]). Here, we limit our

24 definition to the plant and all its symbiotic microbiota. Holobiont is an ecosystem where the host is the biotope

25 and microorganisms are the biocenosis.

26 Interactome: All interactions between organisms within a functional community and their cascade.

27 Intrinsic factors: In the context of the current demonstration, this term is to be understood as the ensemble of all

28 plant characteristics (species, genotype), plant organs (stem, root) and plant-microbe interactions. 
1 Metabolome: The entire biochemical complement present within an organism. Metabolic change is a major

2 feature of plant genetic modification and plant interactions with pathogens, pests, symbionts, free-living 3 microbiota and their environment.

4 Microbiome: Microorganisms and their genetic material (genome, plasmids and mobile elements), short-term or

5 long-term interacting with a particular environment. The diversity in microbiomes between individual plants is

6 huge, and even within a plant there can be extensive variation in their microbiome makeup (i.e. phyllospheric or

7 rhizospheric microbiome).

8 Microbiota : Community of microorganisms (bacteria, archaea, fungi, viruses, protists and other 9 microeukaryota) associated with an organism, here a plant.

10 Mycorrhiza: Intimate association of plant roots with specialized soil fungi. Seven types of mycorrhiza exist, but

11 ectomycorrhiza and arbuscular mycorrhiza are the most common.

12 Phytobiome : According to the Phytobiomes Alliance, it consists in the plant, its environment, the associated 13 microorganisms (i.e., the phytomicrobiome) and all the environment modifications induced by these interactions.

14 Phytomicrobiome: Diverse interacting microscopic organisms associated with a plant living in its environment.

15 Rhizosphere : The volume of soil around living plant roots that is influenced by root activity

16 Signalome: Signal molecules produced withing an organism or during interaction between organisms.

17 Structure: In the field of analysis of the phytomicrobiome, this term provides not only the composition of the

18 taxa and/or functions encountered in the community, but also a quantitative view (i.e., the relative abundance).

19 Symbiont : Organism establishing a close and long-term interaction with its host (here the plant). This

20 interaction can be obligate as in the case of the endosymbiosis.

21 Symbiotic interface (synonym, symbiotic apoplast) : The cellular space between the plant and fungal

22 membranes, delimiting the site of reciprocal nutrient exchanges between the partners. 